\title{
Sistem Pakar Untuk Mendeteksi Kerusakan Pada Sepeda Motor Dengan Menggunakan Metode Forward Chaining Berbasis Web
}

\author{
Januardi Nasir ${ }^{1}$, Zefly Haposan Gultom² \\ ${ }^{1,2}$ Program Studi Teknik Informatika Fakultas Teknik dan Komputer Universitas Putera Batam) \\ Jl. R Soeprapto Tembesi, Batam. telp. 085274121986 \\ e-mail: 1januardinasir@gmail.com
}

\begin{abstract}
Abstrak
Kebanyakan pengendara cenderung menyerahkan sepeda motor kepada mekanik tanpa mengetahui sebenarnya kerusakan tersebut merupakan kerusakan sederhana atau terlalu rumit untuk diperbaiki. Untuk menangani permasalahan tersebut maka dibutuhkan sebuah sistem pakar yang mampu untuk menganalisa, menemukan dan memberikan solusi. Kemampuan seorang mekanik sepeda motor dapat diimplementasikan kedalam sebuah sistem pakar. Datadata yang berkaitan dengan kerusakan sepeda motor 4-tak dianalisa kemudian diolah menggunakan metode sistem pakar forward chaining. Model representasi pengetahuan yang digunakan dalam sistem pakar adalah berbasis kaidah produksi. Desain sistem dilakukan menggunakan bantuan aplikasi starUML. Sistem pakar dibuat menggunakan bahasa pemrograman PHP dan database MySQL sehingga menghasilkan sebuah sistem pakar untuk mendeteksi kerusakan sepeda motor 4-tak menggunakan metode forward chaining berbasis web. Berdasarkan hasil pengujian dan percobaan yang telah dilakukan menunjukkan bahwa sistem pakar untuk mendeteksi kerusakan sepeda motor 4-tak berfungsi dengan baik. Sistem pakar untuk mendeteksi kerusakan sepeda motor 4-tak menggunakan metode forward chaining berbasis web dapat digunakan untuk membantu mekanik dalam menangani permasalahan yang berkaitan dengan sepeda motor dan juga dapat digunakan sebagai sumber pengetahuan mengenai hal-hal yang berhubungan dengan sepeda motor 4-tak seperti gejala kerusakan sepeda motor 4-tak, penyebabnya serta solusi untuk mengatasinya.
\end{abstract}

Kata kunci: Pakar, forward, chaining, kaidah, web,

\begin{abstract}
Most rider tend to give motorcycles to mechanics without knowing that the damage is simple or too complicated to repair. To handle these problems then needed an expert system that is able to analyze, find and provide solutions. The ability of a motorcycle mechanic can be implemented into an expert system. Data related to 4-stroke motorcycle damage were analyzed and then processed using forward chaining expert system method. The model of knowledge representation used in expert systems is based on the rules of production. System design is done using the help of starUML application. Expert systems are created using the PHP programming language and MySQL database so as to generate an expert system to detect 4-stroke motorcycle damage using web-based forward chaining method. Based on the results of tests and experiments that have been done show that the expert system to detect the damage 4-stroke motorcycle is not working properly. The expert system for detecting 4-stroke motorcycle damage using a web-based forward chaining method can be used to assist mechanics in dealing
\end{abstract}


with motorcycle-related issues and can also be used as a source of knowledge on matters relating to 4-stroke motorcycles such as symptoms 4-stroke motorcycle damage, its causes and solutions to overcome them.

Keywords: Expert, forward chaining, rules, web

\section{Pendahuluan}

Sepeda motor merupakan alat transportasi yang digerakkan oleh mesin. Sepeda motor ada dua jenis, yaitu mesin 2-tak dan mesin 4-tak. Disebut mesin 4-tak karena satu siklus motor bensin terdiri dari empat langkah torak. Perbedaan mesin 2-tak dan 4-tak terletak pada siklus yang terjadi pada motor bensin tersebut. Siklus yang terjadi mulai dari menghisap campuran bahan bakar dengan udara, mengkompresikan, meneruskan gaya tekan hasil pembakaran kemudian membuang gas sisa pembakaran dari ruang pembakaran. Selain itu jumlah penggunaan bahan bakar pada mesin 2-tak lebih banyak dari mesin 4-tak. Bagi pengendara yang membutuhkan sepeda motor, maka sepeda motor 4-tak merupakan pilihan terbaik untuk digunakan.

Akan tetapi sering terjadi kendala dari sepeda motor yang mengakibatkan kerusakan sehingga dapat menggangu aktivitas pengendara. hal ini disebabkan oleh kurangnya pengetahuan tentang perawatan kerusakan motor. Kelalaian pengguna sepeda motor dalam melakukan service bulanan dan perawatan rutin mengakibatkan kerusakan dapat timbul. Kebanyakan pengendara cenderung menyerahkan sepeda motor kepada mekanik tanpa mengetahui sebenarnya kerusakan tersebut merupakan kerusakan sederhana atau terlalu rumit untuk diperbaiki. Menyerahkan kerusakan pada mekanik merupakan sebuah langkah praktis dan menjadi sebuah solusi yang paling mudah. Akan tetapi jika pengendara memiliki pengetahuan tentang perawatan kerusakan sepeda motor maka penanganan kerusakan sepeda motor dapat dikerajakan sendiri oleh pengendara tersebut sehingga penanganan kerusakan yang terjadi dapat ditangani dengan sendiri tanpa harus menunggu sepeda motor diperbaiki di bengkel

Untuk menangani permasalahan tersebut maka dibutuhkan sebuah sistem yang mampu untuk menganalisa, menemukan dan memberikan solusi. Kemampuan seorang mekanik sepeda motor dapat diimplementasikan kedalam sebuah aplikasi. Sistem aplikasi yang dapat bekerja sebagaimana manusia atau seorang pakar bekerja dikenal dengan sistem pakar. Sistem pakar yang memanfaatkan teknologi komputer dalam menampung kemampuan/keahlian seorang pakar [1]. dalam hal ini pakar ialah mekanik agar proses menganalisa sebuah masalah dapat diselesaikan oleh aplikasi yang dirancang mewakili pakar dalam menganalisa suatu permasalahan seperti contohnya kerusakan pada sepeda motor. Hal ini dapat membuat mekanik melakukan penanganan dengan efektif dan efisien.

\section{A. Definisi Sistem Pakar}

Salah satu teknik kecerdasan buatan yang menirukan proses penalaran manusia adalah sistem pakar. Pemecahan masalah-masalah yang kompleks biasanya hanya dilakukan oleh seorang pakar [10]. Sistem pakar mencoba mencari penyelesaian yang memuaskan, yaitu sebuah penyelesaian yang cukup bagus agar pekerjaan dapat berjalan walaupun itu bukan penyelesaian yang optimal [3].

\section{B. Kategori Permasalahan Sistem Pakar}

Biasanya aplikasi sistem pakar menyentuh beberapa area permasalahan berikut menurut [5].

1. Interpretasi, menghasilkan deskripsi situasi berdasarkan data-data masukan. 
2. Prediksi, memperkirakan akibat yang mungkin terjadi dari situasi yang ada.

3. Diagnosis, menyimpulkan suatu keadaan berdasarkan gejala-gejala yang diberikan (symptoms).

4. Desain, melakukan perancangan berdasarkan kendala-kendala yang diberikan.

5. Planning, merencanakan tindakan-tindakan yang akan dilakukan.

6. Monitoring, membandingkan hasil pengamatan dengan proses perencanaan.

7. Debugging, menentukan penyelesaian dari suatu kesalahan sistem.

8. Reparasi, melaksanakan rencana perbaikan.

9. Instruction, melakukan instruksi untuk diagnosis, debugging, dan perbaikan kinerja.

10. Kontrol, melakukan kontrol terhadap hasil interpretasi, diagnosis, debugging, monitoring, dan perbaikan tingkah laku sistem.

\section{Struktur Sistem Pakar}

Menurut Sutojo [5]. ada dua bagian penting dari sistem pakar, yaitu lingkungan pengembangan (development environment) dan lingkungan konsultasi (consultation environment). Lingkungan pengembangan digunakan oleh pembuat sistem pakar untuk membangun komponen-komponennya dan memperkenalkan pengetahuan ke dalam knowledge base (basis pengetahuan). Lingkungan konsultasi digunakan oleh pengguna untuk berkonsultasi sehingga pengguna mendapatkan pengetahuan dan nasihat dari sistem pakar layaknya berkonsultasi dengan seorang pakar. Gambar 2.1 menunjukkan komponen-komponen yang penting dalam sebuah sistem pakar [9].

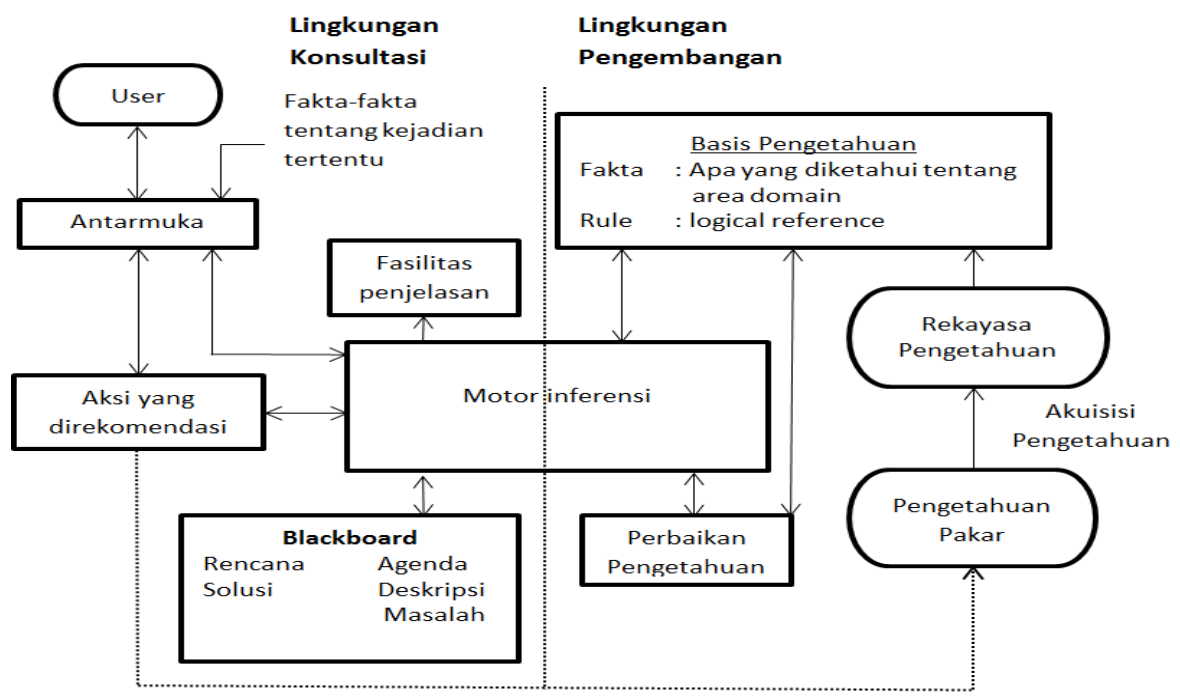

Gambar 1.1 Komponen-komponen sistem pakar Sumber: Sutojo, dkk. (2011: 166)

\section{Forward Chaining (Runut Maju)}

Menurut Sutojo, dkk [5]. Forward Chaining adalah teknik pencarian yang dimulai dengan fakta yang diketahui, kemudian mencocokkan fakta-fakta tersebut dengan bagian $I F$ dari rules IF-THEN. Bila ada fakta yang cocok dengan bagian $I F$, maka rule tersebut dieksekusi. Bila sebuah rule dieksekusi, maka sebuah fakta baru (bagian THEN) ditambahkan ke dalam database [6]. Setiap kali pencocokan, dimulai dari rule teratas. Setiap rule hanya boleh dieksekusi sekali saja. Proses pencocokan berhenti bila tidak ada lagi rule yang bisa dieksekusi.

Konsep ini dapat juga disebut sebagai pencarian yang dimotori data (data driven search). Runut maju melakukan proses perunutan (penalaran) dimulai dari premis-premis atau informasi masukan (IF) terlebih dahulu kemudian menuju konklusi atau derived information (THEN). 
Konsep ini dapat dimodelkan sebagai berikut:

IF (informasi masukan)

THEN (konklusi)

Informasi masukan dapat berupa suatu pengamatan sedangkan konklusi dapat berupa diagnosa sehingga dapat dikatakan jalannya penalaran runut maju dimulai dari pengamatan menuju diagnosa. Pada metode ini, sistem tidak melakukan praduga apapun terhadap konklusi, namun sistem akan menerima semua gejala yang diberikan pengguna lalu sistem akan memeriksa gejala-gejala tersebut dan selanjutnya mencocokkan dengan konklusi yang sesuai [3].

\section{E. Sejarah Sepeda Motor}

Sejarah motor sudah cukup lama sebenarnnya, awalnya dimulai kira-kira akhir abad ke19. Di zaman itu, orang-orang yang kreatif mulai mencoba memasangkan mesin ke sepeda. Inovasi pun berlanjut hingga sekarang, hampir 100 tahun lebih. Hasilnya, motor yang super canggih sudah lazim ditemui, jauh lebih hebat dibandingkan kondisi awal sepeda motor di awal mulanya. Dua orang kreatif fan inovatif yang termasuk dalam golongan orang-orang pertama yang membuat sepeda motor adalah William S. Harley dan Arthur Davidson di Amerika Serikat. Harley dan Davidson ini nantinya akan mengembangkan sebuah sepeda motor yang sampai sekarang masih terkenal, yaitu Harley Davidson.

Ada lagi seorang insinyur berkewarganegaraan Jerman yang pada tahun 1902 mencoba melakukan eksperimen seputar sepeda motor. Nama insinyur ini adalah Mauritz Johann Schulte. Tetapi berbeda dengan Harley dan Davidson yang membuat pabrik sendiri, insinyur ini menjual hasil eksperimennya ke pabrik Triumph Cycle Co. Ltd yang ada di Inggris. Setelah kedua perintis tersebut, maka otomatis muncul banyak pabrik sepeda motor pada awal abad ke-20 di negara-negara maju. Namun, perkembangan pesat sepeda motor baru terjadi setelah masuknya motor hasil pabrik dari negeri Asia, yaitu Jepang. Jepang dnegan pabrik sepeda motor Hondanya mulai melakukan inovasi dengan cara membuat sepeda motor murah, irit, dan bandel mesinnya, untuk kebutuhan transportasi penduduk Jepang setelah perang dunia kedua. Hingga sekarang, tercatat banyak pabrik motor didunia yang menjadikan sepeda motor Jepang sebagai contoh untuk mendesain sepeda motor mereka.

\section{F. Asal Mula Tenaga}

Untuk dapat meluncur di jalan raya, sepeda motor sport memerlukan tenaga gerak untuk melawan gesekan ban dengan jalan, tahanan udara, dan gesekan antar bagian-bagian kendaraan yang berputar. Alat yang dapat membangkitkan daya gerak disebut penggerak utama, yang juga dikenal dengan nama mesin atau motor [7]. Mesin sepeda motor sport menghasilkan daya gerak apabila terjadi proses pembakaran antara campuran udara dan bensin di dalam mesinnya. Tenaga yang berasal dari pembakaran itulah yang digunakan mesin untuk menggerakka sepeda motor. Mesin berfungsi untuk mengubah tenaga dari hasil pembakaran campuran udara dan bensin di dalam suatu ruang bakar menjadi tenaga gerak atau tenaga mekanik. Karena mesin itu menggunakan bahan bakar bensin maka disebut motor bensin [2].

\section{G. Prinsip Kerja Motor Bensin 4-tak}

Sepeda motor sport yang menggunakan motor bensin 4-tak memiliki konstruksi yang terdiri dari katup hisap, katup buang, silinder, torak, cincin torak, batang torak, poros engkol, dan roda penerus [8]. Didalam motor bensin 4-tak, campuran uda dan bensin dibakar untuk memperolah tenaga panas. Jadi supaya motor bensin dapat bekerja, motor bensin 4-tak harus melakukan 4 proses kerja, yaitu:

1. Menghisap campuran udara dan bensin ke dalam silinder.

2. Mengkompresikan gas campuran udara dan bensin agar diperoleh tekanan hasil pembakaran yang tinggi. 
3. Meneruskan gaya tekan hasil pembakaran sedemikian rupa sehingga dapat diubah menjadi tenaga gerak.

4. Membuang gas sisa pembakaran dari ruang pembakaran.

Keempat proses diatas terjadi dalam suatu proses kerja yang disebut siklus. Jadi suatu siklus kerja motor bensin terdiri dari empat proses kerja yang mana masing-masing kerja dilakukan oleh langkah torak penuh. Karena satu siklus motor bensin terdiri dari empat langkah torak maka motor bensin ini disebut motor bensin 4 langkah atau motor bensin 4-tak [2].

H. Bagian Utama Sepeda Motor 4-Tak

1. Mesin

Mesin terdiri dari beberapa bagian, antara lain:

a. Kepala silinder terdiri atas 2 yaitu kepala silinder dengan menggunakan tipe OHC, yaitu dengan poros kam terletak pada kepala silinder dengan pengapian platina, dan kepala silinder menggunakan tipe $\mathrm{OHC}$, yaitu dengan poros kam terletak di kepala silinder dengan pengapian CDI [2].

b. Silinder, merupakan tempat pembakaran campuran udara dan bensin untuk mendapatkan tekanan dan temperatur yang tinggi [2].

c. Bak mesin, yang dikenal dengan istilah carter atau oil pan, merupakan wadah minyak pelumas [2].

d. Sistem pemindah tenaga, berfungsi untuk mengubah tenaga panas hasil pembakaran bahan bakar di dalam ruang bakar menjadi tenaga gerak atau tenaga mekanik [2].

\section{Sistem Katup}

Sistem katup pada sepeda motor 4-tak terdiri dari beberapa bagian, antara lain:

a. Unit katup, untuk membuka dan menutup saluran hisap disebut unit katup hisap sedang unit katup untuk menutup dan membuka saluran buang disebut unit katup buang [2].

b. Unit pembuka katup, berfungsi untuk membuka katup hisap dan katup buang sehingga proses penghisapan campuran udara dan bensin serta pembuangan gas sisa pembakaran dapat berlangsung [2].

\section{Metode Penelitian}

\subsection{Desain Penelitian}

Desain penelitian bertujuan untuk melaksanakan penelitian sehingga dapat diperoleh suatu logika, baik dalam pengujian hipotesis maupun dalam membuat kesimpulan. Langkah-langkah penelitian yang akan dilakukan terlihat pada gambar 2.1 sebagai berikut:

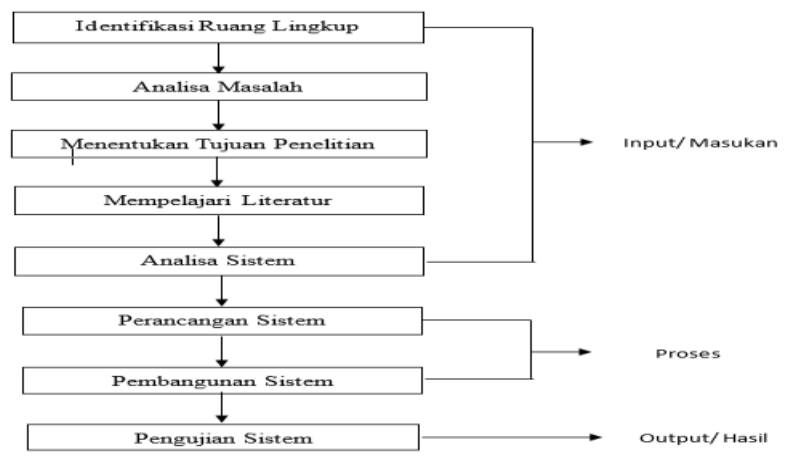

Gambar 2.1 Langkah-langkah Penelitian 


\subsubsection{Operasional Variabel}

Menurut Sudaryono [2], variabel penelitian pada dasarnya adalah segala sesuatu yang berbentuk apa saja yang ditetapkan oleh peneliti untuk dipelajari sehingga diperoleh informasi dan kesimpulannya. Variabel harus didefinisikan secara operasional agar lebih mudah dicari hubungannya antara satu variabel dengan lainnya dan pengukurannya. Adapun manfaat operasional variabel antara lain untuk mengidentifikasi kriteria yang sedang didefinisikan. Dalam penelitian ini operasional variabel yang digunakan adalah kerusakan sepeda motor 4-tak. Jenis kerusakan yang diteliti penulis adalah kerusakan yang umum terjadi pada sepeda motor sport 4-tak [2]. Terdapat dua indikator yang disajikan pada tabel 2.1 sebagai berikut.

Tabel 2. 1 Operasional Variabel

\begin{tabular}{|l|l|}
\hline Variabel & Indikator/Kerusakan \\
\hline \multirow{5}{*}{ Kerusakan Sepeda Motor 4-tak } & Kerusakan pada piston \\
\cline { 2 - 2 } & Kerusakan pada digital CDI \\
\cline { 2 - 2 } & Kerusakan pada katup (valve) \\
\cline { 2 - 2 } & Kerusakan pada digital speedometer \\
\cline { 2 - 2 } & Kerusakan pada rantai mesin \\
\cline { 2 - 2 } & Kerusakan pada rotary transmisi \\
\cline { 2 - 2 } & Kerusakan pada electric stater \\
\cline { 2 - 2 } & Kerusakan pada rem kopling \\
\hline
\end{tabular}

Sumber : Data Penelitian (2017)

Berikut ialah tabel kerusakan dan data gejala kerusakan pada sepeda motor 4-tak.

Tabel 2. 1 Tabel Kerusakan dan Gejala

\begin{tabular}{|c|c|}
\hline Kerusakan & Gejala \\
\hline \multirow{7}{*}{ Kerusakan pada piston } & Motor susah dihidupkan \\
\hline & Tenaga yang dihasilkan lemah \\
\hline & Mesin cepat panas \\
\hline & Busi mudah mati \\
\hline & Asap knalpot berwarna putih \\
\hline & Suara mesin kasar \\
\hline & Oli cepat habis \\
\hline \multirow{5}{*}{ Kerusakan pada digital CDI } & Motor susah dihidupkan \\
\hline & Tenaga yang dihasilkan lemah \\
\hline & Mesin tersendat-sendat saat berjalan \\
\hline & Percikan busi berwarna merah kecil. \\
\hline & Busi mudah mati \\
\hline \multirow{5}{*}{ Kerusakan pada katup (valve) } & Motor susah dihidupkan \\
\hline & Kecepatan gas tidak tetap \\
\hline & Knalpot mengeluarkan asap hitam \\
\hline & Bahan bakar boros \\
\hline & Oli cepat habis \\
\hline \multirow{4}{*}{ Kerusakan pada speedometer } & Lampu speedometer mati \\
\hline & Sensor bensin mati \\
\hline & Jarum speedometer tidak berjalan \\
\hline & Lampu gigi percepatan tidak menyala \\
\hline \multirow{2}{*}{ Kerusakan pada rantai mesin } & Tenaga yang dihasilkan lemah \\
\hline & Mesin tersendat-sendat saat berjalan \\
\hline
\end{tabular}




\begin{tabular}{|c|c|}
\hline & $\begin{array}{l}\text { Suara gemeretak pada rantai terutama pada } \\
\text { suhu dingin. }\end{array}$ \\
\hline \multirow{3}{*}{ Kerusakan pada rotary transmisi } & Mesin tersendat-sendat saat berjalan \\
\hline & $\begin{array}{l}\text { Suara kasar pada saat memasukkan gigi } \\
\text { transmisi }\end{array}$ \\
\hline & Susah memasukkan gigi transmisi \\
\hline \multirow{4}{*}{ Kerusakan pada elektrik stater } & $\begin{array}{l}\text { Tidak ada bunyi saat dihidupkan dengan } \\
\text { elektrik stater }\end{array}$ \\
\hline & $\begin{array}{l}\text { Saat dihidupkan ada bunyi tetapi selip tidak } \\
\text { mau berputar }\end{array}$ \\
\hline & Suara kasar pada dinamo stater \\
\hline & Dinamo stater panas \\
\hline \multirow{5}{*}{ Kerusakan pada rem kopling } & $\begin{array}{l}\text { Saat dihidupkan secara manual tidak ada } \\
\text { tekanan }\end{array}$ \\
\hline & Tenaga yang dihasilkan lemah \\
\hline & Mesin cepat panas \\
\hline & $\begin{array}{l}\text { Timbul hentakan saat pemindahan gigi } \\
\text { transmisi }\end{array}$ \\
\hline & Sering los ketika memasukkan gigi transmisi. \\
\hline
\end{tabular}

Sumber: Data Penelitian (2017)

Berikut adalah tabel kerusakan dan solusi kerusakan pada sepeda motor 4-tak.

Tabel 2. 2 Tabel Kerusakan-Solusi

\begin{tabular}{|c|c|}
\hline Kerusakan & Solusi \\
\hline Kerusakan pada piston & $\begin{array}{l}\text { Ganti piston dengan yang baru, dan piston } \\
\text { harus dalam satu ukuran dengan blok silinder. }\end{array}$ \\
\hline Kerusakan ada digital CDI & Ganti CDI dengan yang baru. \\
\hline Kerusakan pada katup (valve) & $\begin{array}{l}\text { Apabila daun katup aus hanya sedikit maka } \\
\text { perbaikannya dapat dilakukan dengan cara } \\
\text { mensekur lagi. Namun apabila daun katup } \\
\text { pecah maka harus melakukan penggantian } \\
\text { dengan yang baru. }\end{array}$ \\
\hline Kerusakan pada digital speedometer & $\begin{array}{l}\text { Cek kabel speedometer yang terhubung ke } \\
\text { sumbu roda depan, cari tahu apakah kabel } \\
\text { putus atau rusak. Jika putus atau rusak, } \\
\text { lakukan penggantian dengan yang baru. }\end{array}$ \\
\hline Kerusakan pada rantai mesin & $\begin{array}{l}\text { Lakukan penyetelan ulang pada rantai mesin. } \\
\text { Apabila rantai mesin telah mengalami } \\
\text { keausan, maka lakukan penggantian dengan } \\
\text { yang baru. }\end{array}$ \\
\hline Kerusakan pada rotary transmisi & $\begin{array}{l}\text { Silahkan lakukan penggantian dengann yang } \\
\text { baru. }\end{array}$ \\
\hline Kerusakan pada elektrik stater & $\begin{array}{l}\text { Jika hanya brushnya saja yang aus, silahkan } \\
\text { ganti dengan yang baru. Apabila kumparan } \\
\text { (spull) putus sebaiknya dibawa ke mekanik } \\
\text { service dinamo untuk perbaikannya. }\end{array}$ \\
\hline Kerusakan pada rem kopling & $\begin{array}{l}\text { Apabila kondisi rem kopling sudah aus segera } \\
\text { lakukan penggantian dengan yang baru. }\end{array}$ \\
\hline
\end{tabular}

Sumber : Data Penelitian (2017) 


\subsection{Kaidah Produksi}

Kaidah yang akan digunakan dalam sistem pakar untuk mendeteksi kerusakan pada sepeda motor 4-tak adalah sebagai berikut:

1. Kaidah 1

IF motor susah dihidupkan, AND tenaga yang dihasilkan lemah, AND mesin cepat panas, AND busi mudah mati, AND asap knalpot berwarna putih, AND suara mesin kasar, AND oli cepat habis THEN kerusakan pada piston.

2. Kaidah 2

IF motor susah dihidupkan, AND tenaga yang dihasilkan lemah, AND mesin tersendat-sendat saat berjalan, AND percikan busi berwarna merah kecil, AND busi mudah mati THEN kerusakan pada digital CDI.

3. Kaidah 3

IF motor susah dihidupkan, AND kecepatan gas tidak tetap, AND knalpot mengeluarkan asap hitam, AND bahan bakar boros, AND oli cepat habis THEN kerusakan pada katup (valve).

4. Kaidah 4

IF lampu speedometer mati, AND sensor bensin mati, AND jarum speedometer tidak berjalan, AND lampu gigi percepatan tidak menyala THEN kerusakan pada speedometer.

5. Kaidah 5

IF tenaga yang dihasilkan lemah, AND mesin tersendat-sendat saat berjalan, AND suara gemeretak pada rantai terutama pada suhu dingin THEN kerusakan pada rantai mesin.

6. Kaidah 6

IF mesin tersendat-sendat saat berjalan, AND suara kasar pada saat memasukkan gigi transmisi, AND susah memasukkan gigi transmisi THEN kerusakan pada rotary transmisi.

7. Kaidah 7

IF tidak ada bunyi saat dihidupkan dengan elektrik stater, AND saat dihidupkan ada bunyi tetapi selip tidak mau berputar, AND suara kasar pada dinamo stater, AND dinamo stater panas THEN kerusakan pada elektrik stater.

\section{Kaidah 8}

IF saat dihidupkan manual tidak ada tekanan, AND tenaga yang dihasilkan lemah, AND mesin cepat panas, AND timbul hentakan pada saat pemindahan gigi transmisi, AND sering los ketika memasukkan gigi transmisi THEN kerusakan pada rem kopling.

\subsection{Metode Perancangan Sistem}

Perancangan sistem yang diakukan dalam pembangunan sistem pakar mendeteksi kerusakan pada sepeda motor 4-tak menggunakan metode forward chaining adalah pengkodean (nama kerusakan, gejala), memberikan aturan (rule), membuat pohon keputusan. Adapun yang menjadi tahapan yang dilakukan sebagai berikut:

\subsection{Pengkodean}

Pada penelitian ini penulis merancang pengkodean untuk nama kerusakan, gejala kerusakan yang terjadi untuk mempermudah perancangan database yang ada pada sistem. Pengkodean tersebut dapat dilihat dalam tabel dibawah ini. 
Tabel 2. 3 Tabel Kerusakan

\begin{tabular}{|l|l|}
\hline Kode & Nama Kerusakan \\
\hline K001 & Kerusakan pada piston \\
\hline K002 & Kerusakan pada digital CDI \\
\hline K003 & Kerusakan pada katup (valve) \\
\hline K004 & Kerusakan pada digital speedometer \\
\hline K005 & Kerusakan pada rantai mesin \\
\hline K006 & Kerusakan pada rotary transmisi \\
\hline K007 & Kerusakan pada electric stater \\
\hline K008 & Kerusakan pada rem kopling \\
\hline
\end{tabular}

Tabel 2. 4 Tabel Gejala

\begin{tabular}{|l|l|}
\hline Kode & Gejala \\
\hline G001 & Motor susah dihidupkan \\
\hline G002 & Tidak ada bunyi saat dihidupkan dengan elektrik stater \\
\hline G003 & Saat dihidupkan ada bunyi tetapi selip tidak mau berputar \\
\hline G004 & Saat dihidupkan secara manual tidak ada tekanan \\
\hline G005 & Lampu speedometer mati \\
\hline G006 & Lampu gigi percepatan tidak menyala \\
\hline G007 & Sensor bensin mati \\
\hline G008 & Jarum speedometer tidak berjalan \\
\hline G009 & Tenaga yang dihasilkan lemah \\
\hline G010 & Kecepatan gas tidak tetap \\
\hline G011 & Mesin cepat panas \\
\hline G012 & Mesin tersendat-sendat saat berjalan \\
\hline G013 & Mesin sering macet saat jalan \\
\hline G014 & Percikan busi berwarna merah kecil. \\
\hline G015 & Busi mudah mati \\
\hline G016 & Asap knalpot berwarna putih \\
\hline G017 & Knalpot mengeluarkan asap hitam \\
\hline
\end{tabular}


Tabel 2.6 Lanjutan

\begin{tabular}{|l|l|}
\hline G018 & Suara ledakan saat nutup gas pada knalpot \\
\hline G019 & Suara membesar seperti knalpot blong \\
\hline G020 & Suara kasar pada knalpot \\
\hline G021 & Suara mesin kasar \\
\hline G022 & Suara gemeretak pada rantai terutama pada suhu dingin. \\
\hline G023 & Suara kasar pada dinamo stater \\
\hline G024 & Dinamo stater panas \\
\hline G025 & Suara kasar pada saat memasukkan gigi transmisi \\
\hline G026 & Timbul hentakan saat pemindahan gigi transmisi \\
\hline G027 & Sering los ketik memasukkan gigi transmisi. \\
\hline G028 & Susah memasukkan gigi transmisi \\
\hline G029 & Bahan bakar boros \\
\hline G030 & Oli cepat habis \\
\hline
\end{tabular}

Sumber: Data Penelitian (2017)

\subsection{Aturan (Rule)}

Data aturan merupakan data yang berisi relasi antara data-data bagian kerusakan, dan gejala kerusakan yang telah diberikan kode sebelum nya. Relasi antar data tersebut disusun berdasarkan sumber pengetahuan dan fakta yang telah didapatkan. Data aturan ini disusun untuk memudahkan peneliti dalam menyusun kaidah yang akan digunakan sebagai basis pengetahuan dalam sistem pakar pada penelitian ini. Susunan data aturan yang digunakan dapat dilihat pada tabel dibawah ini.

Tabel 2. 7Tabel Aturan

\begin{tabular}{|l|l|}
\hline $\begin{array}{l}\text { Kode } \\
\text { Kerusakan }\end{array}$ & Kode Gejala \\
\hline K001 & G001, G009, G011, G015, G016, G021, G030 \\
\hline K002 & G001, G009, G012, G014, G015 \\
\hline K003 & G001, G010, G017, G029, G030 \\
\hline K004 & G005, G006, G007, G008 \\
\hline K005 & G009, G012, G022 \\
\hline K006 & G012, G025, G028 \\
\hline K007 & G002, G003, G023, G024 \\
\hline K008 & G004, G009, G011, G026, G027 \\
\hline
\end{tabular}

Sumber: Data Penelitian (2017)

\subsection{Pohon Keputusan}

Sebelum membuat pohon keputusan, penulis menyajikan tabel keputusan untuk memudahkan didalam membuat pohon keputusan. 
Tabel 2. 8 Tabel Keputusan

\begin{tabular}{|c|c|c|c|c|c|c|c|c|}
\hline \multirow{2}{*}{ Kode Gejala } & \multicolumn{8}{|c|}{ Kerusakan } \\
\hline & K001 & K002 & K003 & K004 & K005 & K006 & K007 & K008 \\
\hline G001 & $\sqrt{ }$ & $\sqrt{ }$ & $\sqrt{ }$ & & & & & \\
\hline G002 & & & & & & & $\sqrt{ }$ & \\
\hline G003 & & & & & & & $\sqrt{ }$ & \\
\hline G004 & & & & & & & & $\sqrt{ }$ \\
\hline G005 & & & & $\sqrt{ }$ & & & & \\
\hline G006 & & & & $\sqrt{ }$ & & & & \\
\hline G007 & & & & $\sqrt{ }$ & & & & \\
\hline G008 & & & & $\sqrt{ }$ & & & & \\
\hline G009 & $\sqrt{ }$ & $\sqrt{ }$ & & & $\overline{\sqrt{ }}$ & & & $\sqrt{ }$ \\
\hline G010 & & & $\sqrt{ }$ & & & & & \\
\hline G011 & $\sqrt{ }$ & & & & & & & $\sqrt{ }$ \\
\hline G012 & & $\sqrt{ }$ & & & $\sqrt{ }$ & $\sqrt{ }$ & & \\
\hline G013 & & & & & & & & \\
\hline G014 & & $\sqrt{ }$ & & & & & & \\
\hline G015 & $\sqrt{ }$ & $\sqrt{ }$ & & & & & & \\
\hline
\end{tabular}

Tabel 3.7 Lanjutan

\begin{tabular}{|l|l|l|l|l|l|l|l|l|}
\hline G016 & $\sqrt{ }$ & & & & & & & \\
\hline G017 & & & $\sqrt{ }$ & & & & & \\
\hline G018 & & & & & & & & \\
\hline G019 & & & & & & & & \\
\hline G020 & & & & & & & & \\
\hline G021 & $\sqrt{ } 022$ & & & & & & & \\
\hline G023 & & & & & $\sqrt{ }$ & & & \\
\hline G024 & & & & & & & $\sqrt{ }$ & \\
\hline G025 & & & & & & $\sqrt{ }$ & & \\
\hline G026 & & & & & & & & $\sqrt{ }$ \\
\hline G027 & & & & & & & & $\sqrt{ }$ \\
\hline G028 & & & & & & $\sqrt{ }$ & & \\
\hline G029 & & & $\sqrt{ }$ & & & & & \\
\hline G030 & $\sqrt{ }$ & & $\sqrt{ }$ & & & & & \\
\hline
\end{tabular}

Sumber: Data Penelitian (2017) 
Berdasarkan tabel keputusan tersebut maka pohon keputusannya adalah sebagai berikut:

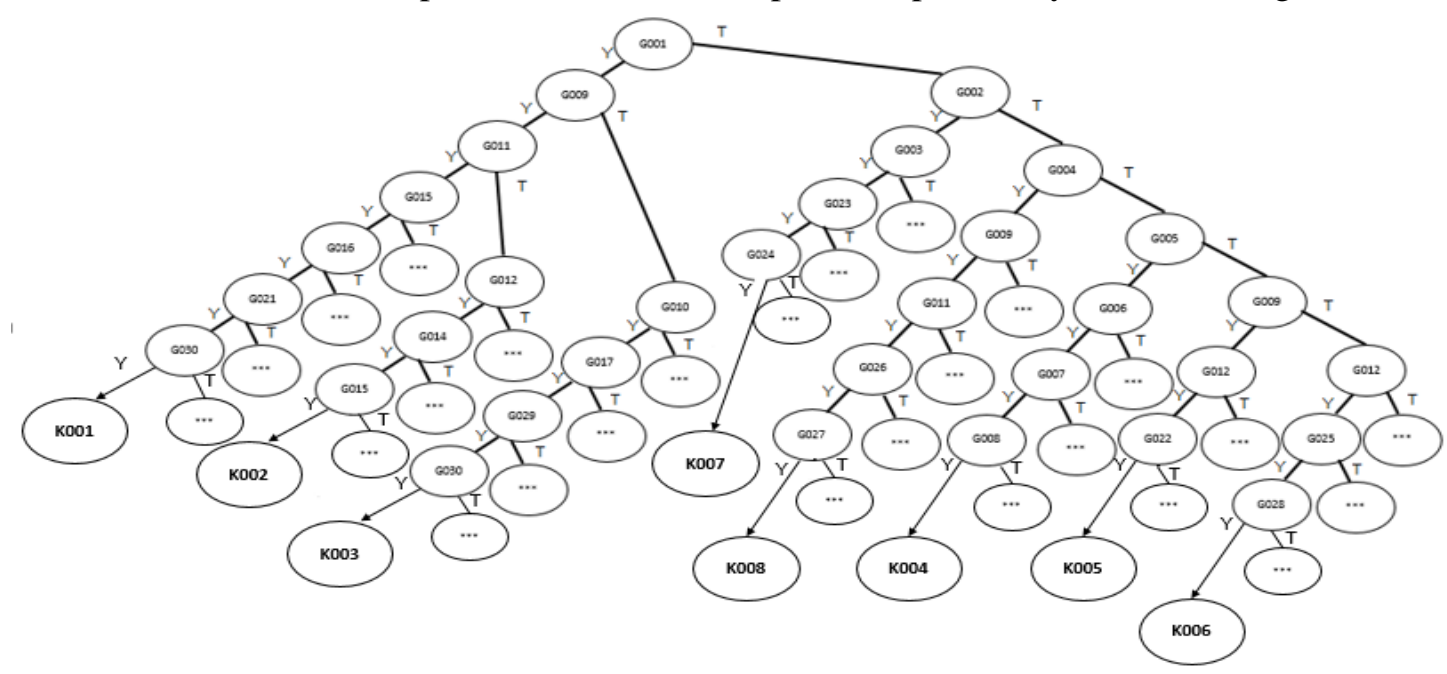

Gambar 2. 2 Pohon Keputusan

Sumber: Data Penelitian (2017)

Data gejala ditentukan sebagai keadaan awal dalam sistem saat melakukan penelusuran sebelum memperoleh keputusan. Jika pengguna memberikan jawaban ya , maka akan berlanjut ke simpul berikutnya dan pertanyaan berikutnya. Jika pengguna memberikan jawaban tidak maka sistem akan langsung memberikan hasil akhir berupa penyebab dan solusi dari kerusakan yang terjadi berdasarkan gejala yang diinput oleh pengguna.

\section{Hasil dan Pembahasan}

Hasil pembahasan pada penelitian ini, Sistem pakar ini menampilkan dua bagian yaitu menu utama dan menu administrator.

\subsection{Desain Database}

Dalam penelitian ini, peneliti membuat desain database menggunakan teknik pemodelan Physical Data Model (PDM) atau model relasional. Berikut ini adalah gambar model relasional yang digunakan dalam sistem pakar ini :

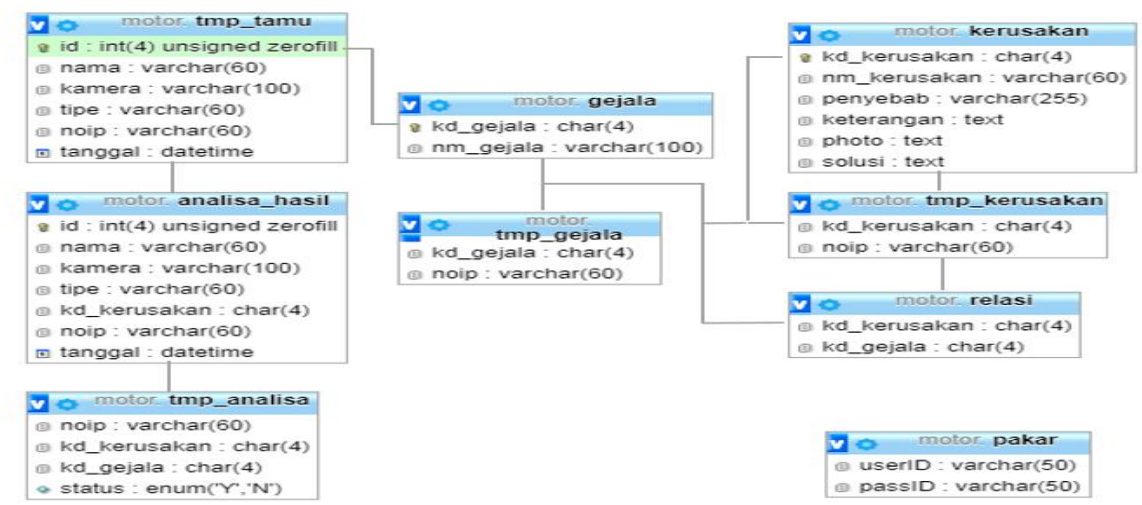

Gambar 3. 1 Physical Data Model

Sumber : Data Penelitian (2017) 
Tabel yang digunakan dalam sistem pakar ini terdiri atas 9 tabel, yaitu analisa_hasil ialah tabel yang digunakan untuk analisa hasil, tmp_tamu digunakan untuk menyimpan daftar tamu, tmp_analisa ialah digunakan untuk menyimpan analisa kerusakan, relasi digunakan sebagai tabel untuk menentukan relasi antara gejala dan kerusakan, gejala digunakan sebagai tabel untuk menyimpan gejala, tmp_gejala digunakan untuk menyimpan gejala, kerusakan merupakan tabel untuk menyimpan data kerusakan, tmp_kerusakan untuk menyimpan kerusakan sementara,dan admin digunakan untuk menyimpan data admin yang dapat membuka sistem pakar.

\subsection{Tampilan Sistem Pakar}

\section{Menu Utama}

Menu utama adalah menu yang pertama muncul pada saat pengguna mulai mengakses sistem. Menu utama dapat diakses oleh pengguna biasa atau tamu maupun administrator.

\section{a. Home}

Home merupakan halaman yang pertama muncul ketika pengguna mengakses sistem. Halaman Home memuat menu yang lain yang dapat diakses oleh pengguna. Halaman Home memberikan secara singkat penjelasan tentang sistem pakar yang sedang diakses oleh pengguna

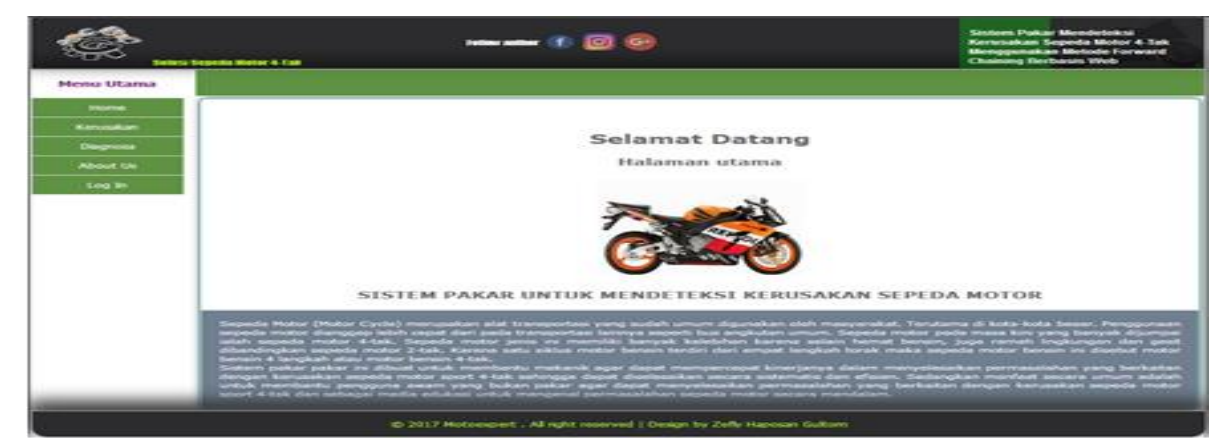

Gambar 3. 2 Halaman Home

Sumber : Data Penelitian (2017)

\section{b. Kerusakan}

Kerusakan merupakan halaman yang memuat tentang penjelasan mengenai kerusakan umum yang dapat terjadi pada sepeda motor 4-tak. Halaman ini dapat diakses oleh pengguna biasa dan juga admin:

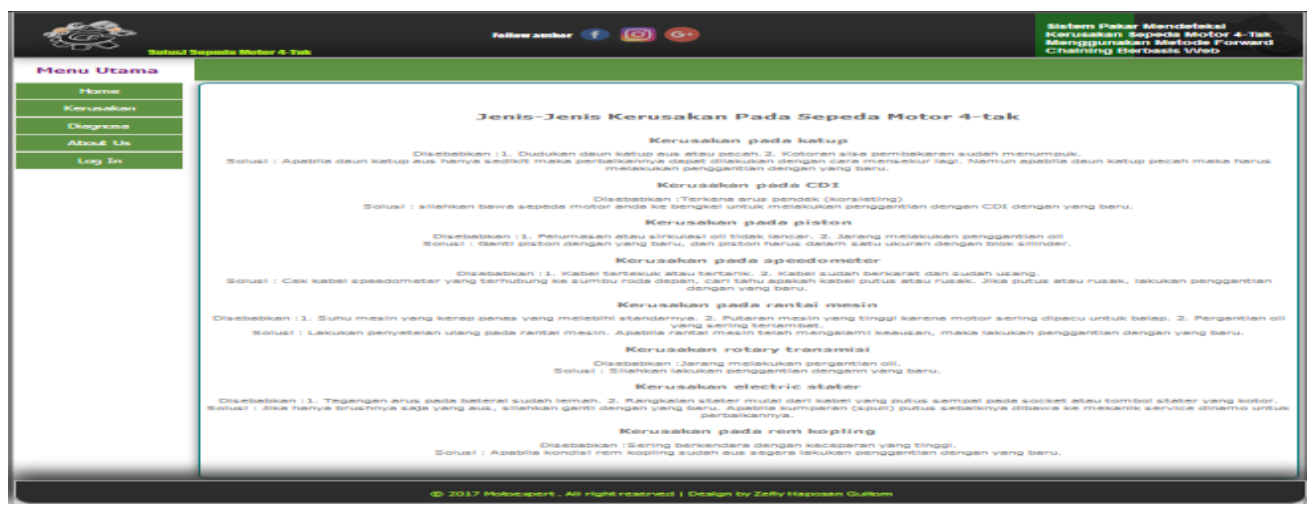

Gambar 3. 3 Halaman Kerusakan 
Sumber: Data Penelitian (2017)

c. Diagnosa

Diagnosa merupakan halaman yang memuat registrasi untuk pengguna dan memunculkan pertanyaan-pertanyaan berupa gejala-gejala yang mengakibatkan kerusakan sepeda motor 4-tak.

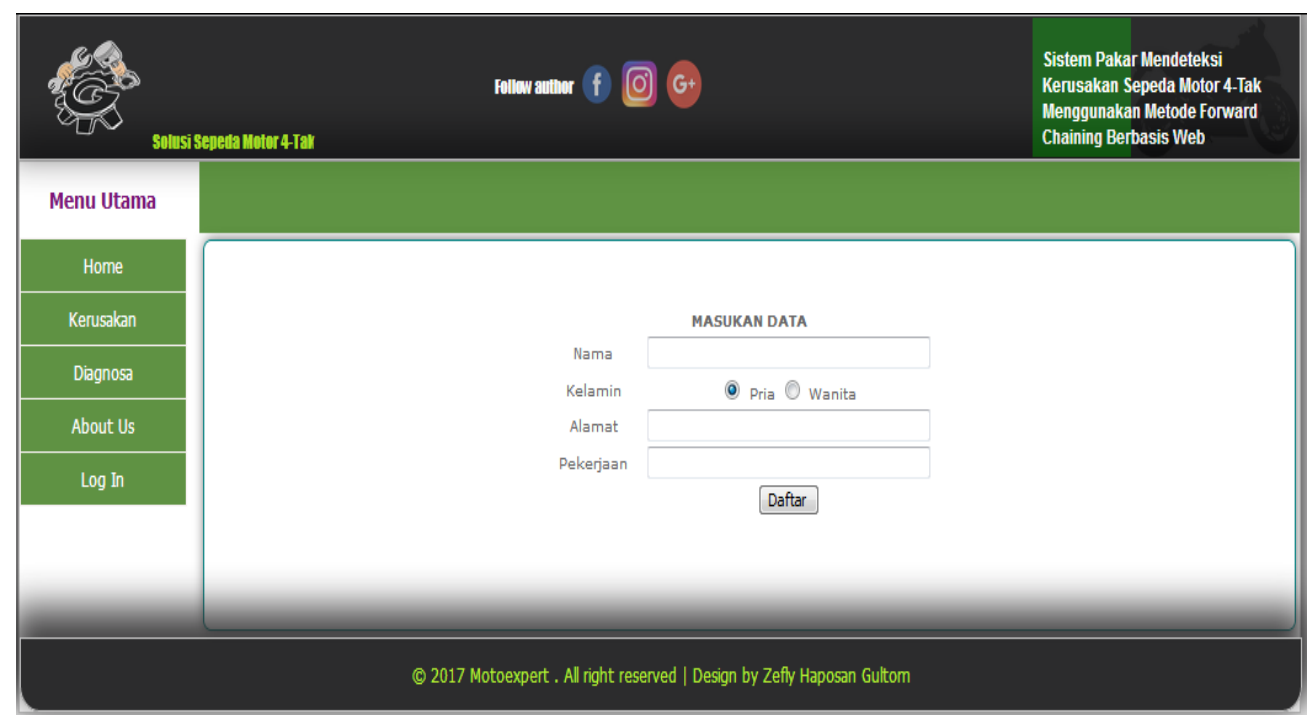

Gambar 3. 4 Halaman Diagnosa

Sumber : Data Penelitian (2017)

d. Hasil Diagnosa

Hasil diagnosa merupakan halaman yang memuat data pengguna dan hasil dari pertanyaan yang telah dijawab dan memberikan jawaban kerusakan yang dapat terjadi.

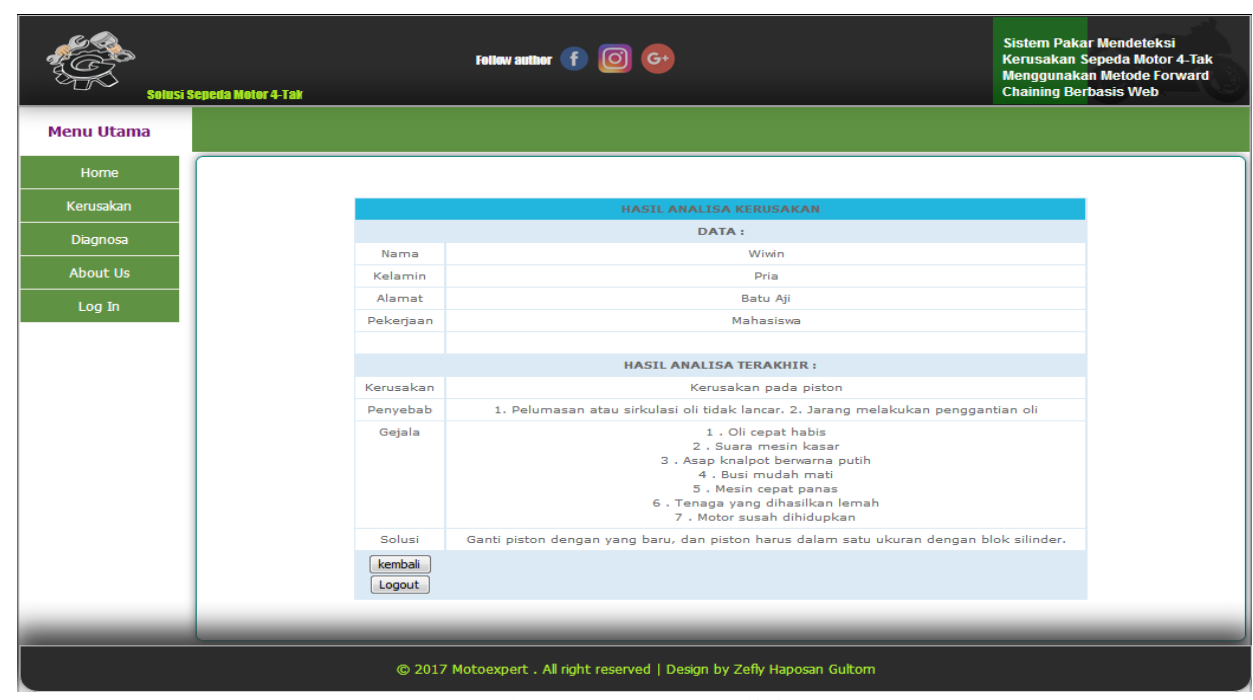

Sumber : Data Penelitian (2017) 


\subsection{Pengujian Analisa Pakar}

Pengujian ini dimaksudkan untuk melihat kemampuan sistem pakar dalam mendeteksi kerusakan pada sepeda motor 4-tak. Pengujian dilakukan dengan melakukan beberapa percobaan dengan memberikan input masukan yang berbeda-beda.

1. Percobaan pertama

Percobaan ini dilakukan dengan memilih gejala dari kerusakan yang pertama yaitu kerusakan pada piston. Gejala yang dipilih adalah sebagai berikut.

1. Motor susah dihidupkan

2. Tenaga yang dihasilkan lemah

3. Mesin cepat panas

4. Busi mudah mati

5. Asap knalpot berwarna putih

6. Suara mesin kasar

7. Oli cepat habis

Berdasakan gejala yang dipilih, maka sistem pakar memberikan kesimpulan bahwa kerusakan yang teranalisa adalah kerusakan pada piston. Berikut hasil keluaran pada sistem.

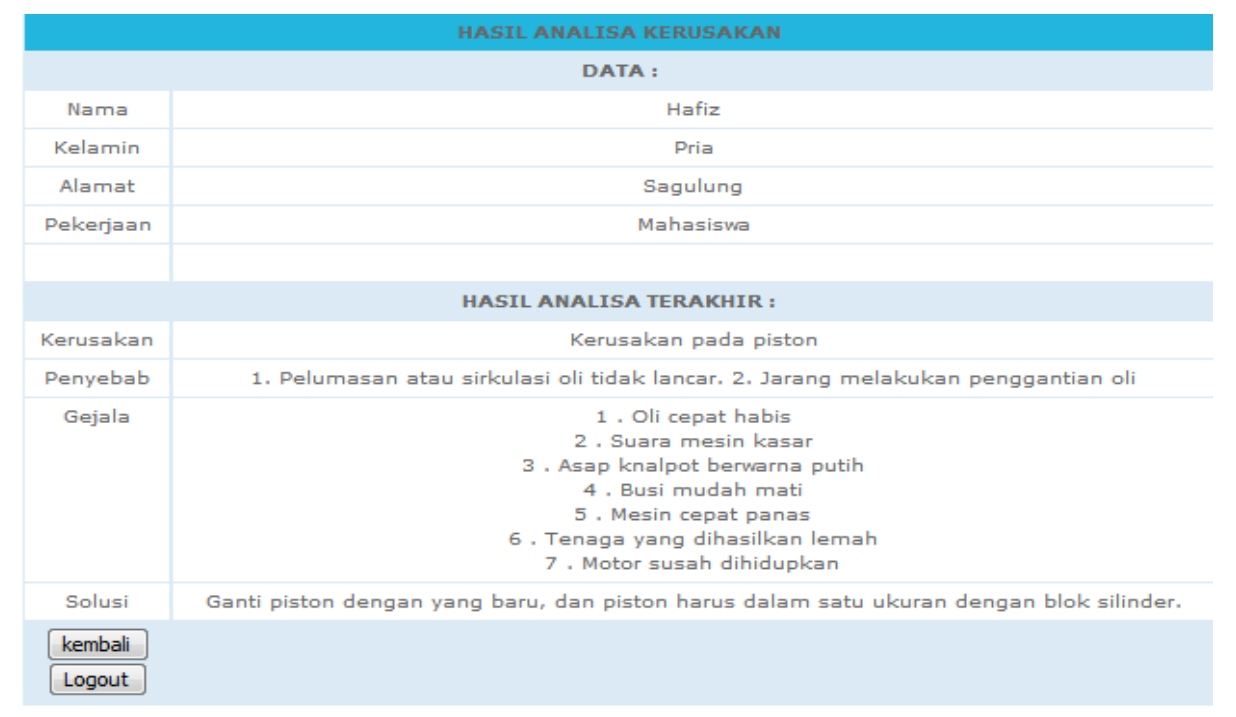

Sumber : Data Penelitian (2017)

\section{Percobaan kedua}

Percobaan kedua dilakukan dengan memilih gejala yang mengarah kepada kerusakan kedua yaitu kerusakan pada digital CDI. Gejala yang dipilih adalah sebagai berikut.

1. Motor susah dihidupkan

2. Tenaga yang dihasilkan lemah

3. Mesin tersendat-sendat saat berjalan

4. Percikan busi berwarna merah kecil.

5. Busi mudah mati 
Berdasarkan gejala yang dipilih, maka sistem pakar memberikan kesimpulan bahwa kerusakan yang teranalisa adalah kerusakan pada digital CDI. Berikut hasil keluaran pada sistem.

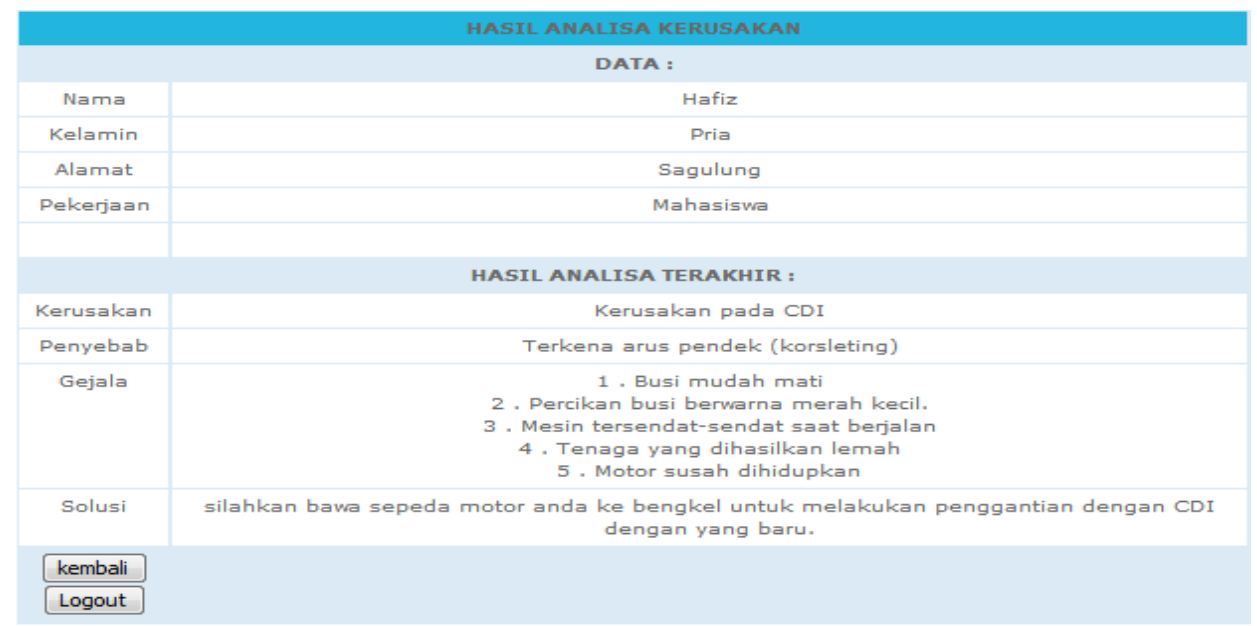

Gambar 3. 7 Hasil Percobaan Kedua

Sumber : Data Penelitian (2017)

\section{Percobaan ketiga}

Percobaan ketiga dilakukan dengan memilih gejala yang mengarah pada kerusakan ketiga yaitu kerusakan pada katup. Gejala yang dipilih adalah sebagai berikut.

1. Motor susah dihidupkan

2. Kecepatan gas tidak tetap

3. Knalpot mengeluarkan asap hitam

4. Bahan bakar boros

5. Oli cepat habis

Berdasarkan gejala yang dipilih, maka sistem akan memberikan kesimpulan bahwa kerusakan yang teranalisa adalah kerusakan pada katup. Berikut hasil keluaran sistem.

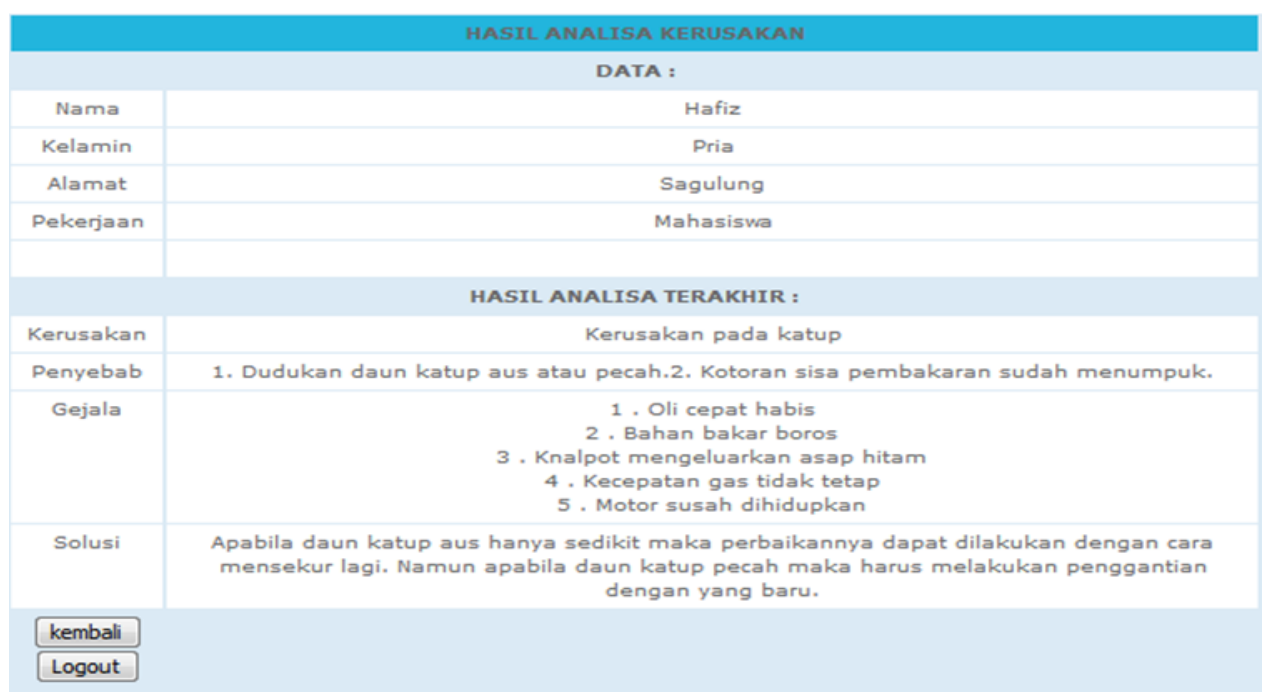

Gambar 3. 8 Hasil Percobaan Ketiga

Sumber : Data Penelitian (2017) 


\section{Kesimpulan}

Subbab ini akan menerangkan temuan-temuan berdasarkan hasil penelitian dan pembahasan dalam penelitian ini. Adapun temuan-temuan tersebut antara lain:

1. Sistem pakar untuk mendeteksi kerusakan sepeda motor 4-tak menggunakan metode forward chaining berbasis web dapat digunakan untuk membantu mekanik dan pengguna sepeda motor dalam menangani permasalahan yang berkaitan dengan sepeda motor 4-tak.

2. Output yang dihasilkan dari sistem pakar dalam penelitian ini berupa hasil diagnosa yang mengandung informasi tentang penyebab kerusakan, gejala dan solusi perbaikan sebagai informasi tambahannya.

3. Sistem pakar pada penelitian ini juga dapat digunakan sebagai media pembelajaran yang dapat menyimpan informasi mengenai hal-hal yang berhubungan dengan sepeda motor 4tak seperti kerusakan yang umum terjadi pada sepeda motor 4-tak, penyebab, gejala dan solusi untuk mengatasinya.

\section{Daftar Pustaka}

[1] Kusrini, Sistem Pakar,Teori dan Aplikasi(Pertama), Yogyakarta: Andi, 2006.

[2] Marsudi, Teknik Otodidak Sepeda Motor Belajar Teknik \& Perawatan Kendaraan Ringan Mesin 4-tak, Yogyakarta: andi, 2010.

[3] S. \&. S. I. Hartati, Sistem Pakar Dan Pengembangan, Yogyakarta: GRAHA ILMU, 2008.

[4] A. M. Rosa, Rekayasa Perangkat Lunak:Terstruktur dan Beriontasi Objek, Bandung: INFORMATIKA, 2013.

[5] Sutojo, Kercedasan Buatan, Yogyakarta: ANDI, 2015.

[6] S. N. Ienaco-, A. S. Pakar, A. Intelligence, and S. Pakar, "Seminar Nasional IENACO2014 ISSN: 2337-4349," 2014.

[7] S. I. Anggraheni Rukmana, "Analisis dan Perancangan Sistem Pakar Untuk Mendiagnosis Kerusakan Sepeda Motor Non Injeksi Pada Bengkel Gemilang Jaya Motor Kabupaten Pacitan,” Indones. J. Comput. Sci., vol. 9330, no. sistem pakar, pp. 1-5, 2012.

[8] Drs. M. Suratman. Servis dan Teknik Reparasi Sepeda Motor. Bandung : Pustaka Grafika. 2009

[9]. J. Nasir, "Sistem pakar konseling dan psikoterapi masalah kepribadian dramatik menggunakan metode forward chaining berbasis web," vol. 3, no. 1, pp. 37-48, 2018.

[10]. J. Nasir, "Analisis Fuzzy Logic Menentukan Pemilihan Motor Honda Dengan Metode Mamdani," Jurnal Edik Informatika, vol. 2, pp. 177-186, 2017 